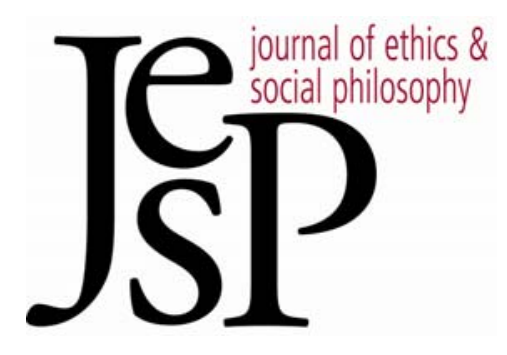

\title{
MOOREAN ARGUMENTS AND MORAL REVISIONISM
}

\author{
BY TRISTRAM MCPHERSON
}

Journal of Ethics \& Social Philosophy

VOL. 3, NO. 2 | JUNE 2009 URL: WWW.JESP.ORG 


\title{
Moorean Arguments and Moral Revisionism
}

\author{
Tristram McPherson
}

And how on earth is it to be decided which of the two things it is rational to be most certain of?

\author{
G. E. Moore, Four Forms of Scepticism (emphasis his)
}

\section{Introduction}

E. MOORE'S LEGACY TO MORAL philosophy has been
both profound and controversial. Most notably, his Principia Ethi-
$\mathrm{c} a$ is often treated as a crucial starting point for work in what is now typically called "metaethics," and metaethicists have returned again and again to defend, debunk or diagnose the appeal of his Open Question argument. This paper examines the implications for moral philosophy of one of Moore's other famous (or, depending upon your tastes, infamous) forms of argument: the table-turning maneuver that he deployed against the epistemological skeptic and the metaphysical idealist.

Against such revisionary metaphysical and epistemological views, Moore claimed that the following constitutes a proof of the existence of his hands, and thereby of the external world:

I can prove now, for instance, that two human hands exist. How? By holding up my two hands and saying, as I make a gesture with the right hand, "Here is one hand," and adding as I make a certain gesture with the left, "and here is another." (1959, 145-6)

The (implicit) remainder of the proof can be represented as follows:

HANDS 1. If the external world did not exist, then I would not have hands

2. I have hands.

3. The external world exists. ${ }^{1}$

Just as some global skeptics and idealists purport to diagnose and correct deep errors in common-sense thinking about the external world, many philosophers have challenged what they take to be common sense about morality. ${ }^{2}$ A particularly radical form of revisionism is metaethical error theory. As I am thinking of it, metaethical error theory consists of two claims. First, error

\footnotetext{
1 Such arguments may strike some readers as absurd. They deserve careful examination, if only because of the number of prominent contemporary philosophers who endorse them. These include Armstrong 1999, Fine 2001, Kelly 2005, Lewis 1996, Lycan 2001 and Pryor $2000,2004$.

2 The views that I have in mind include normative ethical theories that explicitly attack "common-sense morality" (e.g. Parfit 1984, Kagan 1989) and epistemological skepticism about morality (e.g. Sinnott-Armstrong 2006). In this paper I treat metaethical error theory (e.g. Mackie 1977, Joyce 2001) as the exemplary revisionary view, ignoring potentially crucial differences between this and the other cases.
} 
theorists are descriptivists in moral semantics: they claim that in our standard use of moral language, we purport to predicate moral properties such as goodness or wrongness of acts, agents, etc. Second, they are nibilists about moral metaphysics: they claim that nothing has such moral properties. ${ }^{3}$

Someone favorably disposed toward Moore's response to the skeptic and the idealist might be tempted by an analogous response to revisionist views in ethics. Such a response is exemplified by the following argument against error theory:

NO ERROR 1. If metaethical error theory were true, then torturing innocent children just for fun would not be wrong.

2. Torturing innocent children just for fun is wrong. ${ }^{4}$

3. Metaethical error theory is false.

Some recent discussions of metaethical error theory and nihilism can be interpreted as appealing in part to the sort of argument offered in NO ERROR. ${ }^{5}$ The structural similarity between NO ERROR and HANDS can be illuminated by thinking of them as instances of a simple schema. Where a putatively revisionary thesis $(R)$ conflicts with a common-sensical Moorean premise $(M)$, we can represent the form of these arguments as follows:

$\begin{array}{ll}\text { SCHEMA } & \text { 1. If } \mathrm{R} \text { then not }-M \\ & \text { 2. } M \\ \text { 3. Not-R }\end{array}$

I will call instances of this schema Moorean arguments. One might take this shared schematic structure to suggest that Moorean arguments in ethics stand or fall with canonical Moorean arguments like HANDS. 6 In this paper, I argue that this is not so.

Much of the recent literature on Moorean arguments has focused on evaluating an important cluster of related objections to the use of Moorean

${ }^{3}$ For simplicity of exposition, I set aside the possibility here that one could be a nihilist about properties and facts on quite general (e.g. Quinean) grounds. Someone holding such a view could still be a moral realist in virtue of thinking that many moral sentences are true and made so by the way the world is.

${ }_{4}$ Premise 2 is a general moral claim that strikes me as an optimal candidate moral Moorean premise. However, readers with a desire for greater formal symmetry between NO ERROR and HANDS (or strong particularist scruples) should feel free to substitute a highly plausible particular moral claim here.

${ }_{5}$ Compare the arguments suggested by Dworkin 1996, 117-8, Huemer 2005, 117, and Nagel 1997, 115. These arguments each have important features that I cannot address here.

"What "standing" or "falling" amounts to is left intentionally imprecise. Some philosophers think that Moore's arguments succeed at "offense," giving skeptics and idealists reasons to give up their views (Kelly 2005). Others think that while Moore's argument can succeed at "defense" - helping to justify our belief in the external world - it is dialectically ineffective against the skeptic (Pryor 2004). Since I am interested here in the prospects of the Moral Moorean argument relative to those of canonical Moorean arguments like HANDS, I set this important cluster of issues aside. 
arguments. For example, it has been argued that Moorean arguments beg the question, or that they fail to transmit justification from their premises to their conclusions. ${ }^{7}$ Insofar as they have force, such worries typically afflict arguments with the Moorean structure quite generally. The issues raised by these objections are highly complex, and I will not address them in this paper.

I also set aside the crucial general question of how to adjudicate whether a certain view is common-sensical. This issue affects the potential targets of Moorean arguments. For example, George Berkeley claimed that his idealism systematized (rather than revised) common sense, ${ }^{8}$ but would-be Mooreans might be inclined to disagree, and take his view to be an apt target for Moorean arguments. 9 Similar issues arise in evaluating Simon Blackburn's metaethical "quasi-realism" (see his 1993 and others), which is also presented as a hermeneutic account of our ethical discourse, and not as a revision to such talk.

Even if these challenges to the Moorean can be resolved in his favor, his arguments would face a deeper explanatory burden: what explains their alleged positive epistemic force? Many Mooreans claim that this force is considerable. Thus, as we have seen, Moore himself took the argument encapsulated in HANDS to constitute a proof of the existence of the external world. Some contemporary philosophers have taken Moorean arguments to have striking metaphilosophical implications. For example, Tom Kelly argues that, for Moorean reasons, the skeptic "cannot win" in epistemology $(2005,181)$. Even more generally, Kit Fine suggests that the lesson of Moore's arguments is that philosophers ought to be humble about what their arguments could possibly do to undermine what we ordinarily believe $(2001,2)$. Fine and Kelly thus suggest that we do not need to wait for revisionary arguments to appear, and then apply Moorean arguments piecemeal. Rather, they suggest that properly understanding Moorean arguments allows us to know in advance that whole classes of possible revisionary arguments are unsound.

In this paper, I propose that the positive epistemic force of the canonical Moorean arguments can best be understood to rest on asymmetries in indirect evidence $(\$ 2)$. I then argue that this explanation suggests that Moorean arguments are considerably less promising in ethics than they are against Moore's own targets (\$3). Finally, I rebut an important attempt to vindicate the Moorean strategy in ethics by appeal to a reflective equilibrium methodology (\$4).

\footnotetext{
7 For discussion of question-begging, see for example Sinnott-Armstrong 1999; for transmission failure, compare Davies (2000 and elsewhere) and Wright (2002 and elsewhere).

8 An anonymous reviewer correctly points out that if Berkeley were correct on this point, Moorean arguments against Berkeleyan idealism might for this reason be weaker than Moorean argument against metaethical error theory, which is explicitly a revisionary view.

9 Moore himself famously attacked Berkeley's slogan that "esse est percipi" in his 1903 Principia Ethica. However, his argument here does not resemble his canonical Moorean arguments.
} 
As I am most interested here in the comparative merits of the moral Moorean's strategy, I often talk in this paper as if canonical Moorean arguments succeed. However, it should be emphasized that my proposal does not address the sorts of general challenges to the Moorean strategy mentioned above. My account is thus compatible with the claim that the positive epistemic force of canonical Moorean arguments is vitiated by their being objectionably question-begging (for example).

My argument suggests that Moore himself may have better understood the force of this form of argument than some of his contemporary sympathizers. Thus, despite his own robust moral realism, Moore did not deploy such arguments in ethics, and there are no ethical claims among the allegedly common-sensical views that Moore catalogued in his $A$ Defence of Common Sense $(1959,32-59) .{ }^{10}$

\section{The distinctiveness of Moorean arguments}

The standard way to rebut an argument is to attack its premises, thereby explaining why we should refrain from accepting one or more of them. The Moorean instead offers a competing argument for the falsity of the conclusion of a revisionary argument. This strategy would, if successful, show that there must be something wrong with the revisionist's argument. However, unlike the standard sort of rebuttal, the Moorean strategy does nothing to locate the problem.

What might vindicate the Moorean's distinctive strategy? In responding to a skeptical argument that he attributed to Bertrand Russell, Moore offered an instructive comment:

I cannot help answering: It seems to me more certain that I do know that this is a pencil and that you are conscious, than that a single one of these four assumptions [of the skeptical argument] is true, let alone all four.

(1959, 226: emphasis in original)

Three things are notable about this passage. First, Moore does not even suggest here that he has offered an explanation of what has gone wrong with Russell's argument. In this respect, his response brings out the contrast with what I called the standard way to rebut an argument, which purports to locate and explain the error in the argument being rejected. Second, Moore appeals to his judgments about certainty. Finally, he compares how certain he is in the Moorean premise with how certain he is in the grounds for accepting Russell's skeptical conclusion.

I take the final point, that the force of Moorean arguments rests on a comparative judgment, to be important and correct. I will discuss the impli-

10 Contrast Soames 2003, 68-9, who claims that some of Moore's arguments in ethics would have been improved by making them more continuous with his broader common-sensical approach. 
cations of this insight in $\iint 2$ and 3 below. However, there is reason to think that an appeal to certainty cannot fully explain the force of Moorean arguments." It is natural and common to interpret Moore's talk of "certainty" as picking out a degree of psychological confidence in the truth of a claim. ${ }^{12}$ We might thus read Moore as appealing to the norm apportion your belief according to your confidence. 13 This, however, is an extremely dubious epistemic principle, because it is possible - and often paradigmatic of epistemic irrationality - for one's confidence in a thesis to fail to reflect one's evidence for the truth of that thesis. ${ }^{14}$ The confidence principle thus threatens to vindicate reasoning grounded in wishful thinking or denial. However, in such cases, one ought rather to disregard one's confidence in a proposition, and to seek to ameliorate its effects on one's beliefs. ${ }^{15}$

Despite these difficulties, one's relative confidence in the truth of two conflicting claims need not be irrelevant to one's reasonable evaluation of those claims. Insofar as one is epistemically virtuous, one's confidence in a claim will tend to track the quality of the evidence that one has for the truth of that claim. ${ }^{16}$ Thus, confidence may serve as defeasible indirect evidence of the truth of a claim. ${ }^{17}$ My strategy for evaluating candidate Moorean arguments generalizes on this insight.

\section{The generic indicators strategy}

The example of confidence provides a model for the most promising way of understanding the positive epistemic force of Moorean arguments. Our confidence in a proposition provides us with a defeasible indication of the quali-

11 Moore may have been tempted to this view because he saw no way to make further progress in evaluating one's certainty in the truth of a claim. Thus, in the paper just cited, he goes on to ask the apparently rhetorical question: "And how on earth is it to be decided which of the two things [i.e. Russell's skeptical thesis or his own common-sensical premise] it is rational to be most certain of?" (1959, 226; emphasis his). In this paper I suggest the outlines of an answer to this very question.

12 However, for a helpful discussion of different ways of understanding Moore's appeal to certainty, see Kelly 2005.

13 Some contemporary philosophers appear attracted to this norm. For example, Pollock and Cruz claim that "It is reasonable to place more reliance on those beliefs in which we have greater confidence, and when beliefs come in conflict, we decide which to reject by considering which we are least certain of' $(1999,6)$. Similarly, Soames attributes to Moore (and perhaps endorses) the idea that, in case of conflict, "Of course, one ought to give up whichever [claim] one has the least confidence in" $(2003,9)$.

${ }^{14}$ Kelly suggests further worries about the appeal to confidence at 2005, 191-4.

15 This may, of course, be hard to do. For example, being made aware of one's propensity to unrealistically positive self-assessment may not suffice to ameliorate that propensity (compare Elga 2005, 4 and the psychological literature cited there).

16 And perhaps also evidence that one had in the past but has since forgotten. Compare Harman 1986, 41 on the problem of forgotten evidence.

17 I am indebted here to Tom Kelly, who once suggested the slogan "confidence is evidence of epistemic status." He should not be held responsible for how I have developed that suggestion here. 
ty of our evidence for or against that proposition. I propose that we can best understand the epistemic force of a Moorean argument in terms of the indirect evidence that we possess concerning the relative epistemic quality of the relevant Moorean and revisionary claims.

There are two ways of understanding this appeal to indirect evidence, and only one of them is plausible, or has serious Moorean credentials. The first way to understand the appeal would be to suggest that, in order to respond appropriately to a Moorean argument, someone must reason explicitly about the indirect evidence that she possesses. This interpretation would suggest implausibly that only philosophically sophisticated reasoners who have grasped something like my explication of Moorean arguments could deploy such arguments legitimately. I intend a different interpretation, on which reasoners do not need to make explicit the sorts of considerations that I am about to sketch. This is rather the task of philosophers hoping to explain the epistemic force of the Moorean arguments. For ordinary reasoners, it is enough to be inarticulately sensitive to this force. 18

Consider a simple example of how an appeal to indirect evidence might trump the sort of direct evidential considerations provided by an argument. Suppose that, after a dinner out together, we each independently add up our shares of the check, and come to different results. Typically this sort of discrepancy might prompt us to each go back and check our math. However, in some cases, this will be unnecessary. If we both know that you are a significantly better calculator in such contexts than I am, then we might both reasonably accept your calculation as correct on the basis of this evidence. In such a case, my evidence about your abilities affects the weight that I should give to the evidence provided by the results of our respective calculations. This in turn may settle what we should each believe to be a fair division of the bill.

The sort of indirect evidence that I take to be relevant to the evaluation of Moorean arguments is considerably more complex than that suggested in this example. I organize my discussion by examining a series of what I call generic indicators of epistemic quality of a proposition: features the presence or absence of which would, other things being equal, reasonably lead us to raise or lower our estimation of how well supported that proposition is. These features are generic because they tend to indicate epistemically important distinctions across varied epistemic contexts.

I cannot canvass every such indicator here. I focus on a set of five indicators that I take to be the weightiest for the purpose of evaluating Moorean arguments:

1. Relative confidence in the Moorean and revisionary theses.

2. Prevalence of philosophically naïve proponents of the revision.

${ }_{18}$ Note that, by making the Moorean premise salient, Moorean arguments can serve a pragmatic function of making it more likely that reasoners are sensitive to relevant indirect evidence. 
3. Extent and nature of the reorganization of our beliefs required by the revision.

4. Relative consilience of the Moorean premise and the revision with our epistemic paradigms.

5. Vulnerability of the Moorean premise to debunking explanations.

My hypothesis is that whatever epistemic force canonical Moorean arguments have against their revisionary targets can be explained by the fact that, in such arguments, these generic indicators together strongly favor the Moorean premise over the revisionist alternative.

I take the epistemic significance of each of these indicators to be highly plausible, and to be recognized as such by philosophers with divergent commitments in epistemology. (Of course, different epistemic theories will suggest different ways to refine these indicators, and to explain their significance.) In what follows, I offer a (necessarily schematic) defense of each of the indicators in turn. My hope is that this discussion sketches and motivates my view sufficiently to permit at least its provisional evaluation.

First, we are more confident in the truth of some of our beliefs than in others. ${ }^{19}$ While our confidence can sometimes lead us astray, a variety of approaches to epistemology suggests reasons for taking one's confidence to be a (defeasible) indicator of the quality of the evidence at one's disposal. For example, Richard Foley notes that any remotely normal life presupposes trust in one's own epistemic capacities $(2001,3)$. Because we routinely form beliefs on the basis of our confidence in the truth of a proposition, such self-trust in part involves taking one's confidence to be a reliable indicator of one's evidence, other things equal. The epistemic significance of confidence might also be defended on broadly evolutionary ${ }^{20}$ or transcendental ${ }^{21}$ grounds.

The idea that confidence is an indicator of epistemic quality helps to explain both the intuitive force of the attempt to explicate Moorean arguments solely in terms of confidence (mentioned in $\$ 1$ above), and the failure of that attempt - thus, my confidence that $P$ may constitute important indirect evidence that $P$. However, it does not follow from the fact that I am very confident that $P$ that it is reasonable for me to believe that $P$, because this evidence might be outweighed or undercut.

Moore took his arguments to defend the common sense of the folk against philosophical excess, so the appeal to non-philosophical consensus is

${ }^{19}$ Much would need to be done to clarify the relevant notion of confidence. See Foley 2001, 25-7 for some useful remarks.

20 Compare Quine's controversial thesis that we can take "encouragement in Darwin" that our inductive capacities latch on to the world: Quine's idea is that incompetent generalizers tend to die out $(1969,126)$. Creatures with the tendency to radically misapportion their confidence might for analogous reasons tend to be selected against.

${ }^{21}$ For example, mistrust in one's own confidence as a guide to one's evidence might be argued to threaten to undermine one's presupposed status as a reasoner or self-intelligible being (especially given how bad we are at explicitly recalling and weighing our evidence). Such arguments might take inspiration from broadly transcendental considerations offered in $\mathrm{Na}-$ gel 1997 and Davidson 2001. 
Moorean in spirit.22 The idea that broad consensus is epistemically probative can be motivated by the objectionability of epistemic conceit. Thus, as I suggested above, we typically appear to have good reasons to take our own epistemic capacities to be reasonably reliable. Absent some special story, it seems objectionable to take others' epistemic capacities to be significantly inferior to one's own in this respect. ${ }^{23}$

Next, consider the epistemic significance of the sort of adjustment to one's set of beliefs called for by a revisionary argument. One dimension of the scope of such adjustment is the number of particular claims that would require adjustment; perhaps more important is the diversity of such claims. ${ }^{24}$ For example, the difference between skepticism about the external world and skepticism about other minds is not merely quantitative: the former threatens one's beliefs about different kinds of subjects in a way that the latter does not. A Quinean metaphor makes the difference vivid: even a quantitatively massive adjustment like skepticism about other minds might be localized within the "web of belief." By contrast, skepticism about the external world would leave little of the web untouched. The third indicator is based upon the idea that there are defeasible epistemic considerations against a revision as it increases in scope. This indicator reflects the importance of coherence with what one believes as an epistemic desideratum. ${ }^{25}$

Another important indicator of epistemic quality concerns the relative consilience of the Moorean premise and the revisionary thesis with our epistemic paradigms. Briefly, our epistemic paradigms fall into three classes. First, there are paradigmatic sources of evidence: the ordinary inferential practices and epistemic rules of thumb that underwrite our lives as ordinary believers. Second, there are some of our central higher-order beliefs about reliable epistemic procedures. Finally, there are broader paradigms of epistemically successful enquiry, such as scientific enquiry. These sources and procedures comprise much of what we ordinarily take to ground our competence to evaluate epistemic claims. It is plausible that broad inconsistency

22 Moore himself noted another important asymmetry with respect to this indicator in the case of global idealism and skepticism: when considering whether skeptical or idealist hypotheses are true, I cannot consistently take it to count as evidence for such views that they have philosophically sophisticated proponents, for the hypothesis that such views are true is inconsistent with rational belief in the existence of such proponents $(1959,40)$.

23 This claim might appear to involve controversial commitments in the current heated debate concerning the epistemic significance of disagreement with one's so-called "epistemic peers." I would insist rather that the significance of consensus and the objectionability of epistemic conceit form part of the shared intuitive basis that generates the puzzles that drive the current debate over the significance of peer disagreement.

${ }_{24}$ Moore 1959, 32-3 emphasizes the number and diversity of the sort of common-sensical claims that he aims to defend.

25 The idea that coherence is epistemically significant is of course not the unique property of coherentists. Bonjour (in his coherentist phase!) overstates the point only a little when he says that "... [coherence] is, and seemingly must be, a basic ingredient of virtually all rival epistemological theories as well” $(1985,94)$. 
with such paradigms is a powerful indicator that something has gone wrong with a piece of reasoning.

Finally, it counts against a thesis that we seek to deploy in argument that it is vulnerable to debunking explanations. An explanation debunks a proposition if it offers a compelling explanation for the proposition's apparent evidential status that gives us good reason to reject that status. Consider an example: faced with an argument for error theory about beauty, I would be illadvised to deploy I am very beautiful as a Moorean premise (in part!) because this sort of judgment is vulnerable to a quite general debunking explanation grounded in the fact that North Americans tend to overestimate our socially desirable qualities. ${ }^{26}$ Although it may face other difficulties, the potential Moorean premise some sunsets are beautiful is not subject to this one.

A thesis is vulnerable to such debunking explanations just to the degree that there are putative debunking explanations available which are credible hypotheses, given the state of our investigations. Roughly, for a hypothesis to be credible is for there to be something positive to be said (epistemically) for accepting it. This is imprecise, but I hope tolerably so. On the one hand, the mere fact that I can imagine a coherent chain of events that would debunk a thesis does not make that thesis vulnerable. On the other, one does not have to be adequately epistemically justified in believing a debunking explanation in order for a thesis to be vulnerable to it. The significance of vulnerability to debunking explanations is suggested by the notable effort that philosophers dedicate to constructing and rebutting such explanations.

What light do these indicators shed on the canonical Moorean arguments? It is important to note that, in accord with Moore's suggestion noted in $\$ 1$ above, I understand the significance of these indicators as comparative. Our question thus concerns how the Moorean premise fares against the revisionist's thesis relative to each of these indicators. I claim that canonical Moorean arguments like HANDS rate very well in this respect.

First, I am extremely confident in the Moorean premise that I have hands. As Moore would point out, I am likely more confident in it than I am in the premises of any skeptical argument. Second, there is significant interpersonal consensus concerning the Moorean premise (among those who have thought about it), and extremely little philosophically naïve support for the revisionary thesis that the external world does not exist. ${ }^{27}$

Third, accepting the conclusions of Moore's central revisionist targets would arguably require massive and deep adjustment to one's set of beliefs. Thus, giving up the belief in the external world would be no small thing. After all, it calls into question virtually all of our factual judgments about the

${ }^{26}$ Compare again Elga 2005 and the social psychology literature that he draws upon.

${ }^{27}$ Serious doubts about the existence of the external world are perhaps typically limited to philosophers, mystics, the demonstrably insane and perhaps certain adolescents obsessed with The Matrix. 
world. The Moorean premise, by contrast, appears to require little revision to our beliefs.

Fourth, the global skeptical revision threatens to undermine most of our ordinary epistemic paradigms concerning the day-to-day management of belief, and also the status of our best scientific theories as methodological paradigms, at least on the assumption that those theories purport to describe elements of the external world. As I noted at the beginning of $\$ 1$, there may be some tension between the Moorean procedure and our ordinary norms for evaluating arguments, but this tension pales in comparison with the sweeping attack on our epistemic paradigms suggested by global skepticism.

Finally, the Moorean premise I have hands is not the sort of thing that we ordinarily take to be particularly vulnerable to debunking. ${ }^{28}$ Nor, it seems to me, are the sorts of premises that are typically used to construct the best arguments for skepticism and idealism. This indicator, then, will perhaps be a wash.

Together, the indirect indicators suggest a striking asymmetry between the Moorean premise and its revisionary targets. Confidence, consensus, demands to reorganize our beliefs, and consilience with our epistemic paradigms all appear to clearly favor the Moorean. If this is correct, there is a natural explanation of the appeal of the canonical Moorean arguments: these arguments exemplify a nearly best-case scenario relative to the five indicators of epistemic quality introduced above. If the indirect indicators approach is on the right track, this suggests a very strong prima facie case for the Moorean in these cases. (Again, this does not show that the canonical Moorean arguments succeed, as I have not addressed the global challenges to their adequacy mentioned in the Introduction).

\section{Applying the indicators to ethics}

If the explanation just offered is plausible, it suggests a natural way to evaluate candidate Moorean arguments: examine how they fare relative to these same generic indicators of epistemic quality. In this section, I examine how these indicators apply to our exemplary moral Moorean argument No ER-

28 One of the changes in the dialectic concerning external world skepticism since the EarlyModern period is that the debunking appeal to perceptual illusion that was part of the skeptical corpus has been thoroughly domesticated: cases where perception is unreliable have been delimited, and the only dialectical force of such appeals in the current debate is that they remind us that our perceptual capacities are fallible. It might be thought that evil demon and vat hypotheses are important debunking explanations for the belief that I have hands. However, this would be a mistake, as we typically have no specific evidence in favor of these hypotheses, and they are thus not credible in the sense introduced above. This does not undercut the (non-debunking) role of such hypotheses in canonical skeptical arguments: skeptics typically argue that the mere possibility (or compatibility with our evidence, etc.) of such hypotheses, together with certain general epistemological premises, entails that we lack knowledge of the external world. 
ROR, and to an analogous non-moral case. I argue that examination of these cases casts serious doubts on the Moorean strategy in ethics.

The Moorean premise of NO ERROR does very well with respect to confidence, the first indicator that I discussed. I am very confident that it is wrong to torture a child just for fun. Non-philosophical consensus is a trickier matter. On the one hand, few would disagree with the Moorean premise just stated, so the Moorean premise does well with respect to this indicator. However, there are two respects in which the moral Moorean is in a weaker position relative to this indicator than the Moorean about hands.

First, as every ethics professor knows, belief in error theory and other revisionary views about ethics is not restricted to philosophical sophisticates. Rather, these views are seen by many non-philosophers as elements of a clear-eyed realism about the world. Thus, we arguably do not see a broad non-philosophical consensus concerning the falsity of the revisionist's thesis here. ${ }^{29}$ Second, there is a broader worry: while the claim that it would be wrong to torture innocent children for fun is widely shared, moral judgments on the whole are arguably paradigmatically controversial. This raises at least some worry that lack of controversy about specific moral judgments like this one is accidental, and this may undermine the force of consensus.

Consider next the implications of the error-theoretic revision for our beliefs. Moral error theory requires sweeping revision to a merely local part of our belief system: our moral beliefs, and beliefs about morality. It thus involves a much less radical revision to our beliefs than global skepticism. One might object that there is a strong analogy between the global threat to our practical commitments entailed by error theory, and the global threat to our beliefs about the world entailed by skepticism about the external world..$^{30}$ However, even on the most generous interpretation of this idea, there are two deep asymmetries.

First, the error theory under examination attacks only morality, and not practical rationality per se (compare Joyce 2001). Such a view thus does not by itself pose a threat to our practical commitments that is analogously global to the threat posed by external world skepticism. ${ }^{31}$ Second, much of our ordi-

${ }^{29}$ Bill Wilcox suggests a natural objection here. Surely we also typically discover in our introductory ethics classes that our students' attraction to views like error theory is seemingly founded on confusion. Can we use this sort of debunking explanation to undercut the appearance of disagreement just noted? One problem with this suggestion is that it would generalize in a way disadvantageous to the Moorean. Thus, even students who accept views that I take to be correct frequently offer poor reasoning in support of these views. I take it that the inability to articulately defend one's pretheoretical views is ubiquitous, and should not be taken to debunk those views. I also take it that the Moorean should be especially suspicious of the requirement that we be able to offer an articulate defense of our views, as the Moorean can perhaps best be seen as the defender of the inarticulate folk against what he sees as the clever and articulate sophistry of the skeptic.

${ }^{30} \mathrm{I}$ thank a number of commenters, and especially Gabe Mendlow, for pressing this point.

${ }^{31}$ Note that this depends in part on the correct view of the relationship between morality and practical reason. For example, certain Kantian views of practical reason suggest that all 
nary moral knowledge concerns specific real cases (for example, slavery in the antebellum South) which be would be undermined by skepticism about the external world. ${ }^{2}$ By contrast, very little of our ordinary non-moral knowledge of the world would be undermined by accepting metaethical error theory. This is a clear respect in which the one revision is more global than the other. Note that this is a comparative claim: it is consistent with the obvious fact that accepting metaethical error theory would require a very significant modification to most people's beliefs.

More strikingly, metaethical error theory also fails to threaten our epistemic paradigms as deeply as global skepticism. For example, beliefs about our perceptual access to medium-sized dry goods, the legitimacy of induction and the deliverances of physics would all presumably remain unaffected by the acceptance of metaethical error theory.

Finally, I take the special vulnerability of our moral judgments to debunking explanations to be perhaps the most profound problem for the use of Moorean arguments against moral revisionism. Ethical beliefs are subject to an extraordinary variety of interesting and relevantly local candidate debunking explanations. I note only a few exemplary debunking arguments here.

First, the fact of widespread moral controversy appears to make moral judgments especially vulnerable to debunking explanations. Thus, one of John Mackie's central arguments for error theory appeal to what he takes to be massive and apparently rationally irresolvable moral disagreement, and to the idea that the best explanation of this disagreement lies in the sensitivity of our moral judgments to the different ways of life that people participate in (1977, 36-38). ${ }^{33}$ This explanation of moral controversy raises a worry about even apparently uncontroversial moral claims, such as the claim that it would be wrong to torture innocent children for fun. Thus, Mackie might explain

practical reasoning presupposes the correctness of categorical moral norms (compare for example Korsgaard 2003, 113-5). If this were true, moral error theory would generalize to entail error theory about practical reason.

32 Bill Wilcox suggests that one might deny this claim by insisting that such "ordinary moral knowledge" is really complex knowledge, and the truly moral proposition involved is something completely general that would not be undermined by such skepticism. I find such a view independently implausible. I am sympathetic to the idea that the truth of particular moral claims may be ultimately explained in terms of necessarily true general moral principles. However, this does not make knowledge of specific moral claims any less moral knowledge. Further, I take it that correctly identifying general moral principles is a rare and impressive philosophical achievement, and one that is not required in order to have specific moral knowledge such as the knowledge that slavery in the American context was wrong. If this is true, skepticism about the external world would undercut a great deal of our moral knowledge.

33 Some have thought that the variation of moral norms across historical and social contexts suggests that the norms accepted as moral at a time and place are simply a result of arbitrary social changes. Pinker goes so far as to suggest a sort of "Law of Conservation of Moralization" that regulates this drift, ensuring that some socially undesirable outcomes are treated as matters of sin and virtue as opposed to matters of preference $(2008,34)$. 
the lack of controversy here by appeal to the overlap between ways of life in different human communities.

Second, as a significant body of empirical research has shown, the psychological mechanisms that underwrite our moral judgments seem to be intertwined with emotion (e.g. Greene 2007, Haidt 2001, Hauser 2006). Indeed, elicited disgust reactions have been shown to have some effect on the moral judgments that people make (Wheatley and Haidt 2005). It is typical to take such emotionally driven effects to be distorting factors in our cognitive lives. Some philosophers, including Josh Greene, have sought to develop debunking explanations of some of our moral judgments on the basis of their vulnerability to emotion.

Third, our moral judgments also appear especially vulnerable to psychological pressures that we might think typically tend to distort our judgments. Consider first the effect of psychological pressure to rationalize one's behavior. Taking oneself to be doing bad things makes for cognitive dissonance. Sometimes this causes one to change one's behavior in order to resolve the tension. However, we have all seen instances of the other way of resolving the tension: people changing their values to rationalize their own wants, or the activities called for by their social roles. Examples of this sort of phenomenon can be drawn from the stock characters of folk sociology: the ardent union leader changing his views following promotion to management, or the college anarchist who graduates, gets a job and becomes a conservative. Both ordinary folk and moral philosophers have recognized this sort of worry. For example, it is generally recognized that partiality can be a significant distorting factor in our moral thinking (compare Rawls 1951, 182 and SinnottArmstrong 2006, 195-7).

Finally, one might worry that our normative judgments are subject to distortion as the result of interpersonal pressure or manipulation. For example, compare Gilbert Harman's bargaining explanation for our belief in a moral asymmetry between harming and refusing to help. Harman suggests that the asymmetry arose because, while everyone would benefit from a prohibition on harming, an enforced requirement to aid would be costly but not advantageous to the wealthy. The idea is that the existence of a robust prohibition on harming and a modest requirement to aid result from a tacit compromise between the rich and poor $(1977,110)$. It is arguably natural to read this as a story of ideological influence, as Walter Sinnott-Armstrong (2006, 208-9) does, rather than as an account of the basis of legitimate moral norms, as Harman's own view suggests.

Examples like this suggest a general worry: that there are powerful social agents who have an interest in bringing the contents of our normative judgments in line with their concerns, and that mechanisms of social influence on belief permit them to exercise such interests. Karen Jones suggests that such concerns about ideology may be "...the source of much ordinary skepticism about moral knowledge" $(2006,66)$. If this is correct, this form of debunking 
argument has both philosophical resonance and an imaginative grip on ordinary folk.

Each of these potential sources of debunking explanations concerning our moral judgments is controversial. This brief survey also barely scratches the surface of the range of debunking explanations of our moral judgments that have been offered. ${ }^{34}$ These challenges to the epistemic quality of our moral judgments arguably leave our epistemic paradigms untouched. They thus suffice to mark what I take to be an important asymmetry with the canonical cases in which Moorean arguments appear strongest. My claim here is not that these debunking arguments are sound. Rather, it is that the moral Moorean faces a wider variety of putative debunking arguments which have some claim to be credible hypotheses, and whose existence thus gives us some reason to lower our estimation of the epistemic quality of moral Moorean premises.

The preceding survey suggests that moral Moorean arguments like No ERROR compare unfavorably with Moore's canonical arguments, relative to the generic indicators discussed. However, this does not suffice to show that moral Moorean arguments are not epistemically adequate responses to revisionist arguments in ethics. This is because we require some means of assessing how far a Moorean argument could diverge from the ideal case of the canonical arguments, while remaining compelling.

Ideally, I would explore the answer to this question by examining a broad range of analogous cases. For the sake of brevity, however, I will consider only two further exemplary cases. My first case aims to make a very modest point: that some arguments that fit the simple Moorean schema discussed in the Introduction clearly fail. The second case bears important analogies to NO ERror, and thus helps to provide insight into the question just posed.

The clearest cases where structurally Moorean arguments fail are those in which pretheoretically seemingly obvious claims have been disproven by scientific investigation. I take the history of science to suggest many such cases: consider the surprising discoveries that have been made concerning the size of heavenly bodies, the roughly spherical shape of the earth, and the relativity of motion. As an example, suppose that one is confronted for the first time with the evidence for a well-supported atomic theory which entails that most of the volume of ordinary objects is made up of empty space. One might respond with the following Moorean argument:

BRICK 1. According to contemporary physical theory, this brick is not solid, but is rather mostly made up of empty space.

34 Debunking explanations that have been proposed regarding morality range from the sophisticated and narrowly focused undermining of specific intuitions that is part of the normative ethicist's stock in trade to the more sweeping undermining arguments that have been put forward by philosophers, historians, anthropologists, social theorists, feminists, psychologists and others. 
2. But [raps knuckles on brick for emphasis] this brick is as solid as could be. No empty space here.

3. Contemporary physical theory is mistaken.

I hope that you will agree that this argument does not succeed. (If you think that I have ill-described this scenario, feel free to replace it with another example of a surprising scientific discovery.)

We can tell a plausible story about why BRICK fails by appealing to the generic indicators. The Moorean premise may (at the relevant time) have scored well on confidence and consensus. However, the revision to our beliefs is very local (it affects only our views about solidity), and the revisionist thesis has epistemic paradigms on its side: since Galileo we have learned to accord the results of increasingly robust experimental methodology epistemic priority over our intuitive interpretations of physical phenomena. Finally, there is a clear debunking explanation of the would-be Moorean premise here: once we realize that there is a contrast between being solid and having no visible holes, it become plausible that the Moorean premise here may rest upon a conflation of these two properties. A plausible explanation of why BRICK fails is that, together, these indicators favor the revisionist over the Moorean.

Some philosophers attracted to Moore's argumentative strategy describe Moorean premises (such as I have hands) as "Moorean facts." BRICK helps to remove two temptations that such talk might appear to invite. First, such talk might trick us into thinking that we have a pretheoretical grip on which propositions are Moorean facts. Second, it might lead us to think that it is some absolute or intrinsic feature of a proposition that makes it a Moorean fact. Both of these ideas are mistaken.

First, "Moorean fact" is a term of art: it plausibly refers to a proposition that would play the required role in a sound Moorean argument. We should thus not assume that, having been given examples such as here's a hand and things move, we are able to intuitively sort further cases with respect to this category. BRICK is helpful here, because it casts doubt on the idea that we can intuitively identify Moorean facts. Thus, it may have been reasonable for a $17^{\text {th }}$ century enquirer, lacking a competing argument from physical theory, to believe that the solidity of a granite slab was (in effect) a Moorean fact.

Second, as I have suggested, the epistemically crucial features of Moorean arguments are most plausibly understood in relative, and not absolute, terms. The Moorean argument in BRICK fails. However, an analogous argument with the same "Moorean" premise might have succeeded in a different context. For example, the evident solidity of a brick might have played a central role in a rationally persuasive rebuttal to a flimsy revisionary argument based in speculative metaphysics. (Such an argument would, of course, need to be deployed before physical theorizing undermines the plausibility of the Moorean premise.) This is because we assess each of the five epistemic indi- 
cators that I have discussed comparatively, when we use them to evaluate a Moorean argument.

BRICK thus shows us that some putative Moorean arguments fail, and that the generic indicators account can explain the failure as well as the success of such arguments. Our next case sheds more direct light upon the moral Moorean's case.

Suppose that one were confronted with an argument for mereological nihilism, and responded with the following Moorean argument:

TABLE 1. According to mereological nihilism, the only material objects that exist are simples: objects with no parts.

2. This table exists, and it is pretty clearly a complex material object: the legs even detach.

3. Mereological nihilism is false.

This argument has the by-now familiar Moorean structure. As most of us are presumably quite confident of analogues of the second premise of this argument, confidence and consensus may favor the Moorean here. Nonetheless, I think that TABLE is intuitively an unsatisfactory response to arguments for mereological nihilism, and that reflection on the remaining indirect indicators can help to explain why.

Consider first the sort of reorganization of our beliefs called for by mereological nihilism. Accepting mereological nihilism would commit one to altering a huge number of one's beliefs. However, those beliefs would all concern the existence of apparently complex objects. Further, there is a simple recipe for retaining almost all of the structure of one's beliefs here: one replaces each belief that there is a complex $F$ with the belief that there are simples arranged F-wise. This suggests that the reorganization called for by mereological nihilism is, while broad, not very radical. Further, given the transformation suggested by this recipe, one's methodological paradigms would not be threatened. ${ }^{35}$ Accepting mereological nihilism would thus not threaten our beliefs in nearly the deep and systematic way that global skepticism would.

Another reason to be suspicious of TABLE can be brought out by noting a point often made in metaontological debates: that it is unclear how adequately we understand the contrast between the claim that there are simples arranged tablewise, and the claim that those simples constitute a distinct object: the table. ${ }^{36}$ This suggests a potentially powerful debunking argument against the putative Moorean premise: we are certainly confident that there are tables around rather than, say, cleverly disguised Martians or nothing at all. Perhaps we mistake this contrastive confidence for confidence that there are

35 Setting aside the crucial complication that our best physical theories may not be compatible with an ontology of simples!

36 Putnam $(2004,37)$ is perhaps blunter than most mereological quietists when he says: "to ask whether mereological sums really exist would be stupid." 
tables simpliciter, because we are simply not used to thinking about mereological hypotheses. ${ }^{37}$

None of this suggests that mereological nihilism is correct. My claim is rather that, even if we accept canonical Moorean arguments like HANDS, we need not accept TABLE as an analogous rebuttal to serious arguments for mereological nihilism. I claim that the contrast between the generic epistemic indicators as they apply to these cases helps to explain why TABLE fails. ${ }^{38}$

This conclusion is important, because TABLE bears important similarities to our moral Moorean argument NO ERROR, with respect to these epistemic indicators. In both cases, there is at least close to a non-philosophical consensus about the Moorean premise, and I presume that we are asymmetrically confident in that premise. I have also suggested that in both cases the revisionist challenge to our beliefs is broad but in an important sense localized, and that our strongest epistemic paradigms are not threatened by the revision. Finally, I have suggested that the Moorean premise in TABLE is vulnerable to a very salient debunking explanation. The moral Moorean premise appears more vulnerable in this respect, given the variety of credible putative debunking explanations of our moral judgments that are on offer.

I argued that the pattern in the generic epistemic indicators explains the failure of TABLE. If this is so, the parallels just sketched suggest poor prospects for Moorean arguments in ethics. This is because, as I have just suggested, the very features which explained the epistemic inadequacy of TABLE are also in place in the moral case.

\section{The appeal to reflective equilibrium}

Someone sympathetic to moral Moorean arguments might suggest that the indirect indicators strategy is the wrong way to assess the positive epistemic force of Moorean arguments. In this section, I briefly discuss what I take to be the most important alternative explanation of this force. This explanation appeals to a broader "reflective equilibrium" conception of philosophical methodology.

One of the most ambitious contemporary defenders of Moorean arguments is Tom Kelly. Kelly argues that the epistemic norm that explains the force of Moorean arguments is the following: a Moorean argument is a good

37 Note that this sort of contrastive debunking also threatens the moral Moorean argument. Thus, I am sometimes tempted by the thought that my confidence in the moral Moorean premise really just reflects my certainty that torturing children for fun is wrong rather than okay, or that, if anything is wrong, torturing children for fun is wrong. I cannot believe that the true moral theory could tell me that torturing children is okay. However, error theory need tell me no such thing: it may undercut claims of moral permissibility along with claims of wrongness.

$38 \mathrm{~A}$ few people have suggested to me that they take TABLE to be a successful Moorean argument. I find this intuitively implausible. However, it is worth noting that if these philosophers were correct about TABLE, then, other things being equal, my generic indicators approach would suggest a more optimistic conclusion about moral Moorean arguments. 
one just in case it is more reasonable to retain the common-sensical thesis rather than the conjunction of the skeptical premises (Kelly 2005, 194). Call this Kelly's norm. Kelly himself suggests that this norm is "close to trivial," simply stating the epistemically obvious.

This does not mean that it is always impossible to usefully apply Kelly's norm. After all, we often have a clear grip on which of two conflicting claims is better epistemically supported, and, in these cases, Kelly's norm seems easy to apply. However, Kelly's norm is, in many crucial cases, of little help. What we would like is a more explanatorily substantive account of how to apply such a norm. The indirect indicators strategy is intended to play this role. Kelly himself suggests that a more substantive vindication of the force of Moorean arguments can be found by appealing to John Rawls' method of reflective equilibrium.

Kelly is not alone in appealing to reflective equilibrium as a methodological foundation for Mooreanism. ${ }^{39}$ For example, Michael Huemer makes a similar appeal while defending a broadly Moorean response to moral nihilism: "It is highly unlikely that it [the method of reflective equilibrium] could ever lead us to endorse [moral] nihilism, as the latter requires a rejection of our entire body of moral beliefs." $(2005,117)$. I shall call this explanation of the alleged success of moral Moorean arguments the conservative bypothesis.

In this section, I argue for two claims. More narrowly, I argue that the conservative hypothesis fails. This suggests that moral Moorean arguments cannot be saved by appeal to reflective equilibrium. More broadly, I argue that, insofar as the method of reflective equilibrium is plausible, it fails to offer the more substantive guidance that Kelly takes it to provide in assessing Moorean arguments.

The conservative hypothesis appears attractive as a defense of the Moorean strategy in ethics because the method of reflective equilibrium can appear to have two features. First, especially in ethics, it is often taken to be something close to methodological common ground.40 Second, reflective equilibrium can appear to be conservative in just the way that Huemer suggests is required to vindicate Mooreanism. However, this combination of appearances is deceptive. In order to see why, we must examine the progress of one central debate about reflective equilibrium.

In barest outline, Rawls' method of reflective equilibrium proposes that we decide moral questions by following a three-stage procedure. First, we assemble our "considered judgments" about particular moral cases. Rawls uses this term to refer to those judgments that one stably affirms in condi-

${ }^{39}$ Compare similar suggestions in Pollock and Cruz 1999, 7n3 and perhaps also in Dworkin 1996, 119.

${ }^{40}$ Two examples suggest the flavor of philosophical endorsements of the method. First, Smith suggests that Rawls' account of reflective equilibrium successfully systematized our methodological platitudes in ethics (1994, 40). Second, Kagan suggests that all practicing normative theorists are at least implicitly committed to something very similar to the method $(1998,16)$. 
tions which minimize what we intuitively take to be sources of error, such as strong emotion or self-interest (1951, 181-3; see also 1999b, 42). The second stage is to find general moral principles that explain these judgments. The final stage is to adjust some of the considered judgments and principles, as necessary, in order to produce "equilibrium": roughly, coherence within this system of judgments and principles (1951, 184-9).41

Rawls himself insisted upon a crucial refinement to this method, telling us to aim at what he called a "wide" (rather than "narrow") reflective equilibrium. ${ }^{42}$ An equilibrium is wide if it is reasoned to from informationally ideal circumstances. For Rawls, these ideal circumstances consist in one's initial stock of considered judgments being augmented by exposure to all plausible conceptions of morality and all reasonable arguments in favor of (and, one supposes, against) each of these conceptions (1999b, 43; 1999a, 289).

Norman Daniels, an influential champion of wide reflective equilibrium, puts the point of the revision forcefully:

Narrow equilibrium... is particularly ill-suited to provide a basis for a justificational argument... If we have reason to suspect that the initial judgments are the product of bias, historical accident, or ideology, then these elementary coherence considerations alone give us little basis for comfort. $(1979,258 \mathrm{n} 4)$

The move from narrow to wide reflective equilibrium provides some relief from the conservatism of the narrow method. ${ }^{43}$ For example, it permits the use of debunking arguments in one's moral methodology. The fact that it permits us to utilize such debunking arguments is a weighty reason to prefer the wide version of the method to the narrow variant.

The crucial question is thus whether a wide reflective equilibrium method would vindicate Huemer's conservative hypothesis. This is a difficult question, but one reason to think that it would is that the imagined wide reflective equilibrium ideal is still fundamentally dispositional: we are asked to imagine an agent exposed to a massive set of new information, and what that agent would then do to render her set of judgments coherent. Someone might reasonably conclude from reflecting upon her own psychology that it is unlikely that she would ever be moved by error-theoretic arguments. After all, if one has not been moved by such arguments in the past, one might have at least modest grounds for supposing that one would not be moved by them in the future.

This line of reasoning thus appears to support the conservative hypothesis. However, it does so only in virtue of what some philosophers have taken

${ }^{41}$ I am abstracting away from a host of fascinating features of Rawls' 1951 proposal here, to focus on those issues most relevant to moral Mooreanism.

${ }^{42}$ Rawls introduces the term "wide reflective equilibrium" in 1999a, 289. However, he makes it clear there that he intends this to have the same sense as what he calls the "philosophically relevant" equilibrium in 1999b, 43.

${ }^{43}$ Not everyone is convinced that wide reflective equilibrium suffices to escape this problem. See Hare 1973, Singer 1974 and Copp 1985 for classic statements of remaining worries. 
to be the central problematic feature of the reflective equilibrium methodology. I noted in $\$ 1$ that the problem with the simplistic confidence account of the force of Moorean arguments is that we might be irrationally confident. The problem here is analogous: just as we might be irrationally confident, we might be disposed to react irrationally to our evidence in the imagined informationally ideal circumstances.

Steven Stich and Richard Nisbett famously argued that such a possibility is not mere philosophical fantasy. Ordinary reasoners display robust endorsement of irrational inference patterns such as the gambler's fallacy (1980, 192-3). The existence of rationally compelling arguments against these inference patterns renders it unreasonable to utilize the gambler's fallacy pattern of inference. However, such arguments are not guaranteed to be psychologically effective merely in virtue of being rationally compelling. Nor are bad arguments in favor of the gambler's fallacy guaranteed to be psychologically ineffective $(1980,196-7)$. All will depend on how we are disposed to react to such evidence. Stich and Nisbett thus suggest that, given the actual behavior of ordinary reasoners, it may be empirically plausible that objectionable principles such as the gambler's fallacy could survive into a wide reflective equilibrium.

One could develop the reflective equilibrium methodology in a way that explicitly addresses this concern. The natural way to do so would be to eliminate the residue of dispositional elements that remain in the wide reflective equilibrium account. Thus, instead of asking what one would in fact do if exposed to assorted arguments for and against the gambler's fallacy (where one possible answer is: fall even harder for it than before!), ask what one ought to do when presented with such evidence. However, as it is stripped of its dispositional elements, the method of reflective equilibrium becomes, like Kelly's norm, more plausible at the expense of being less informative. At the limit, it will become hard to distinguish the view from the platitudinous norm apportion your beliefs to your total evidence. ${ }^{44}$ This modification would thus make it unclear whether reflective equilibrium would vindicate Moorean arguments, in ethics or elsewhere.

This, I take it, is how it should be. It is helpful in this context to consider an analogy to astrological belief. Absent peculiar and powerful misleading evidence, I take the believer in astrology to be another clear example of someone whose defense of his beliefs on Moorean grounds should fail. If not, the Moorean strategy provides only the coldest of comfort in the face of revisionary argument. Indeed, I take it that an attempted Moorean defense of astrological belief should fail even if:

1. the believer is extremely confident in the astrological claims, such that no new information would in fact change his mind, and

2. debunking astrology involves rejecting the "entire body" of his astrological beliefs.

${ }^{44}$ Compare Siegel 1992 for this worry. 
Stripped of its dispositional elements, the method of reflective equilibrium is compatible with debunking astrology even when conditions (1) and (2) hold. ${ }^{45}$ If this is so, the fact that moral judgments satisfy conditions analogous to (1) and (2) cannot underwrite the Moorean strategy in ethics, if the method of reflective equilibrium is the correct explanation of the force of such a strategy. This spells trouble for the moral Moorean, because it was exactly these conditions that Huemer used to motivate the conservative hypothesis explanation of the success of Moorean arguments in terms of reflective equilibrium.

\section{Conclusions}

The extension of Moorean arguments to ethics can appear at first blush to be inevitable. This, I think, is partly a result of an ambiguity that has bedeviled expressions of the basic Moorean idea. This is the ambiguity of terms like "certainty" and "plausibility," which we can understand as indicating either a certain positive psychological attitude toward a proposition, or that proposition's possessing a certain evidential status. Slurring over this ambiguity can make the moral Moorean strategy look like a sure-fire winner, as we are indeed extremely confident in some of our moral judgments. I have suggested that once the distinction is made, confidence has to compete with other indicators of epistemic quality. I have then argued that this framework for understanding the force of Moorean arguments casts serious doubts on the Moorean strategy in ethics.

I take this to be a significant result in moral epistemology, but it is important to clarify what does and does not follow from it. First, this conclusion does not entail the success of any sort of revisionism in ethics. Nothing I have said here suggests that moral Moorean arguments never rationally compel assent. As I have emphasized, the indicators are to be evaluated comparatively, so Moorean arguments in ethics may be sufficient to rebut relatively weak revisionary arguments. Nor does my argument militate against the use of non-Moorean arguments that rebut the premises of relevant revisionary arguments. Thus, I take there to be a number of attractive rebuttals to the standard arguments that have been offered for metaethical error theory.

45 Scanlon offers a helpful discussion of the astrological believer and reflective equilibrium in 2003, 145-6. It is revealing that, in explaining what he takes to be the Rawlsian case for asymmetry between ethics and astrology, Scanlon appeals to Rawls' claim that our conception of justice has no controversial empirical or metaphysical presuppositions. If Scanlon is correct, a Rawlsian response to error theory is not Moorean. Rather, it involves fleshing out a broad conception of the nature of morality that shows the error theorist to argue from an allegedly mistaken presupposition about the metaphysical commitments implicit in moral judgment. 
All this has simply supposed for the sake of argument that the Moorean has a sufficient answer to the various global objections to the Moorean argument form. The discussion here thus does not entail a view about the ultimate success of the canonical uses of Moorean argument. However, it does help to clarify the dialectic. By casting the issue in terms of indirect evidence, my account suggests on the one hand that would-be Mooreans have to be circumspect about what they seek to include in what David Armstrong called the "Moorean corpus" $(1999,79)$ : not just anything that they are overwhelmingly confident in will do. On the other hand, the account makes the Moorean appear less like an unreasonable dogmatist, by pointing out that in the canonical Moorean arguments, there is an array of powerful indirect evidence providing implicit support for the Moorean's maneuver. This may make it easier for the Moorean to resist some of the charges that are levied against her view. It may also be helpful to the Moorean cause to be able to explain in a principled way (as I have sought to do) why her view does not generalize to cases like BRICK or the defense of astrology.

If the generic indicators account is the right way to understand Moorean arguments, it may even help to vindicate the more ambitious Moorean methodological programs that I briefly noted in the Introduction. These programs involved drawing lessons from Moorean arguments to explain not only why certain particular revisionist arguments fail, but also to vindicate broader dismissals of whole classes of revisionism. I have suggested that the canonical Moorean premises score nearly maximally on the whole range of indirect indicators. Very few philosophical theses can make such a claim. The generic indicators account could be taken to suggest that in virtue of this, the prospects for a successful philosophical argument for a revisionist conclusion in Moore's canonical cases are hopelessly dim.

I used Moore's question "And how on earth is it to be decided which of the two things it is rational to be most certain of?" $(1959,226)$ as an epigraph for this paper. I take this to be a real question, and not a rhetorical invitation to despair. My hope is that this paper has contributed in a small way to answering it. ${ }^{46}$

\section{Tristram McPherson}

University of Minnesota Duluth

Department of Philosophy

tristram@d.umn.edu

$46 \mathrm{I}$ am indebted to many people for helpful comments on previous drafts of this paper. These include Bill Fitzpatrick, Gabe Mendlow, John Maier, Philip Pettit, Mark Schroeder, Prerna Singh, Jason Ford, Mark Newman, Sean Walsh, Bill Wilcox, David Plunkett and an anonymous reviewer for JESP. I also want to thank audiences at the Minnesota Philosophical Society and at Princeton University's Department of Philosophy and Center for Human Values for helpful comments on this material. Finally, I owe special thanks to Tom Kelly for helping to inspire my interest in this topic, and for providing both feedback and a powerful foil to my views as they developed. 


\section{Bibliography}

Armstrong, David. 1999. “A Naturalist Program: Epistemology and Ontology.” Proceedings and Addresses of the APA. 73(2): 77-89.

Blackburn, Simon. 1993. Essays in Quasi-Realism. Oxford: Oxford University Press.

Bonjour, Laurence. The Structure of Empirical Knowledge. Cambridge, MA: Harvard University Press, 1985.

Copp, David. 1985. "Considered Judgment and Moral Justification: Conservatism in Moral Theory." Morality, Reason, and Truth: New Essays on the Foundations of Ethics. Eds. David Copp and David Zimmerman. Totowa, N.J.: Rowman \& Allanheld. 141-68.

Daniels, Norman. 1979. "Wide Reflective Equilibrium and Theory Acceptance in Ethics." Journal of Philosophy. 76(5): 256-82.

Davidson, Donald. 2001. "Radical Interpretation." Inquiries into Truth and Interpretation, 2 nd Ed. Oxford: Clarendon Press.

Davies, Martin. 2000. "Externalism and armchair knowledge." New Essays on the A Priori. Eds. Paul Boghossian and Christopher Peacocke. Oxford: Oxford University Press. 384-414.

Dworkin, Ronald. 1996. "Objectivity and Truth: You'd Better Believe It.” Philosophy \& Public Affairs. 25(2). 87-139.

Elga, Adam. 2005. "On overrating Oneself... and Knowing it.” Philosophical Studies. 123: $115-124$.

Fine, Kit. 2001. “The Question of Realism.” Philosophers' Imprint. 1(1).

Foley, Richard. 2001. Intellectual Trust in Oneself and Others. Cambridge: Cambridge University Press.

Greene, Joshua. 2008. “The Secret Joke of Kant's Soul.” Moral Psychology Vol. 3: The Neuroscience of Morality. Ed. Walter Sinnott-Armstrong. Cambridge, MA: MIT Press. 3580.

Haidt, Jonathan. 2001. "The Emotional Dog and its Rational Tail: a Social Intuitionist Approach to Moral Judgment." Psychological Review. 108(4): 814-834.

Hare, R. M. 1973. "Critical Study: Rawls' Theory of Justice.” Philosophical Quarterly. 23: 144-155; 241-251.

Harman, Gilbert. 1977. The Nature of Morality. New York: Oxford University Press.

---. 1986. Change in View: Principles of Reasoning. Cambridge, MA: MIT Press.

Hauser, Mark. 2006. Moral Minds. New York: Ecco.

Huemer, Michael. 2005. Ethical Intuitionism. New York: Palgrave Macmillan.

Jones, Karen. 2006. "Moral Epistemology." Oxford Handbook of Contemporary Philosophy. Oxford: Oxford University Press. 63-85.

Joyce, Richard. 2001. Myth of Morality. Cambridge: Cambridge University Press.

Kagan, Shelly. 1998. Normative Ethics. Boulder, CO: Westview.

---. 2001. The Limits of Morality. Oxford: Oxford University Press.

Kelly, Thomas. 2005. "Moorean Facts and Belief Revision, or can the Skeptic Win?" Philosophical Perspectives. 19: 179-209.

Korsgaard, Christine. 2003. "Realism and Constructivism in Twentieth-Century Moral Philosophy." Journal of Philosophical Research APA Centennial Supp.: Philosophy in America at the Turn of the Century. 99-122.

Lewis, David. 1996. "Elusive Knowledge." Australasian Journal of Philosophy. 74(4): 549567.

Lycan, William. 2001. "Moore against the New Skeptics." Philosophical Studies. 103(1): 3553.

Mackie, J. L. 1977. Ethics: Inventing Right and Wrong. Harmondsworth: Penguin.

Moore, G. E. 1903. “The Refutation of Idealism.” Mind 12.48. October 1903. 433-453.

---. 1959. Philosophical Papers. London: George Allen \& Unwin.

Nagel, Thomas. 1997. The Last Word. New York: Oxford University Press. 
Parfit, Derek. 1984. Reasons and Persons. Oxford: Clarendon.

Pinker, Steven. 2008. "The Moral Instinct." New York Times Magazine, January 13, 2008: 32-58.

Pollock, John and Joseph Cruz. 1999. Contemporary Theories of Knowledge. Oxford: Rowman and Littlefield.

Pryor, James. 2000. "The Skeptic and the Dogmatist." Nô̂s. 34(4). 517-549.

---. 2004. “What's Wrong with Moore’s Argument?” Philosophical Issues. 14: 349-378.

Putnam, Hilary. 2004. Ethics without Ontology. Cambridge, MA: Harvard University Press.

Quine, W.V. 1969. Ontological Relativity. New York: Columbia University Press.

Rawls, John. 1951. "Outline of a Decision Procedure for Ethics.” Philosophical Review. 60: 177-97.

---. 1999a. "The Independence of Moral Theory." Collected Papers. Cambridge, Mass: Harvard University Press. 286-302.

---. 1999b. A Theory of Justice. (Rev. ed.). Cambridge, MA: Belknap.

Scanlon, Thomas. 2003. "Rawls on Justification." Cambridge Companion to Rawls. Cambridge: Cambridge University Press. 139-67.

Siegel, Harvey. 1992. "Justification by Balance." Philosophy and Phenomenological Research. 52(1): 27-46.

Singer, Peter. 1974. "Sidgwick and Reflective Equilibrium." Monist. 58(3): 490-517.

Sinnott-Armstrong, Walter. 1999. "Begging the Question." Australasian Journal of Philosophy. 77: 174-91.

---. 2006. Moral Skepticisms. New York: Oxford University Press.

Smith, Michael. 1994. The Moral Problem. Oxford: Blackwell.

Soames, Scott. 2003. Philosophical Analysis in the Twentieth Century Vol. 1. Princeton: Princeton University Press.

Stich, Stephen and Richard Nisbett. "Justification and the Psychology of Human Reasoning." Philosophy of Science. 47, 1980: 188-202.

Wheatley, Thalia and Jonathan Haidt. 2005. "Hypnotic Disgust makes Moral Judgments more Severe.” Psychological Science. 16(10): 780-784.

Wright, Crispin. 2002. "(Anti-)sceptics simple and subtle: Moore and McDowell." Philosophy and Phenomenological Research. 65: 330-48. 